\title{
Serviço de transporte de cargas agropecuárias e os investimentos necessários no Brasil
}

\section{Agricultural cargo service transportation and investment needed in Brazil}

\author{
Guilherme Asai \\ Carlos Alberto Piacenti ${ }^{2}$ \\ Weimar Freire da Rocha $\mathrm{Jr}^{3}$ \\ Homero Fernandes Oliveira ${ }^{4}$
}

\section{RESUMO}

O objetivo do presente trabalho foi traçar um panorama atual do serviço de transporte de cargas agropecuárias devido à importância econômica que a agropecuária e a logística possuem no Brasil. Através disso foi possível constatar a existência de fatores limitantes que ocasionam perdas nas vantagens competitivas e comparativa adquiridas na produção agrícola brasileira. Para minimizar estas perdas, investimentos em infraestrutura nos serviços de transportes são indispensáveis, porém estão aquém do necessário para a realidade atual.

PALAVRAS-CHAVES: Logística; serviço de transporte; investimentos; fatores limitantes.

\begin{abstract}
The objective of the present work was to outline a current panorama of the agricultural cargo transportation service due to the economic importance that agriculture and logistics have in Brazil. Through this, it was possible to verify the existence of limiting factors that cause losses in the competitive and comparative advantages acquired in Brazilian agricultural production. To minimize these losses, investments in infrastructure in transport services are indispensable, but they are below what is necessary for the current reality.
\end{abstract}

KEYWORDS: Logistics; transportation service; investments; limiting factors

JEL: Q10; R40; R53.

\footnotetext{
${ }^{1}$ Possui graduação em Engenharia Agronômica pela Escola Superior de Agricultura Luiz de Queiroz (ESALQ/USP), doutorado em Desenvolvimento Regional e Agronegócios na Universidade Estadual do Oeste do Paraná (Unioeste), mestrado em Agronegócios pela Escola de Economia de São Paulo da Fundação Getúlio Vargas (EESP/FGV) e pós-graduação em administração e finanças pela Escola de Administração de Empresas de São Paulo da Fundação Getulio Vargas (FGV EAESP). E-mail : guilherme.asai@yahoo.com

${ }^{2}$ Doutor Honoris Causa em Economia pela Universidad Nihon Gakko; Doutor em Economia Aplicada (2009) e Mestre em Economia Rural pela Universidade Federal de Viçosa (1988), Graduado em Ciências Econômicas pela Faculdade de Ciências Econômicas do Sul de Minas (1984). Professor Associado da Universidade Estadual do Oeste do Paraná - UNIOESTE. E-mail: piacenti8@yahoo.com.br ${ }^{3}$ Engenheiro Agrônomo formado pela Universidade Federal de Lavras (1989), Mestre em Economia Agrária (Economia Aplicada) pela Universidade de São Paulo (1994) e Doutor em Engenharia de Produção pela Universidade Federal de Santa Catarina (2001). Professor Associado da Universidade Estadual do Oeste do Paraná onde leciona no Curso de Ciências Econômicas . Docente do Programa de Pós-graduação em Desenvolvimento Regional \& Agronegócio (Mestrado e Doutorado). E-mail : wrochajr2000@yahoo.com

${ }^{4}$ Unioeste. E-mail : homero.oliveira@unioeste.br
} 


\section{INTRODUÇÃO}

No mundo globalizado o fluxo de pessoas, de mercadorias e de serviços está cada vez mais ativo. Na economia mundial, Ballou (2010) indica que a logística é parte integrante dessa economia ao englobar atividades relacionadas ao fluxo de produtos e serviços, tais como o transporte, estoque e comunicação. Tratada como uma ciência, Antón (2005) indica que a logística estuda como mercadorias, pessoas e informações superam o tempo e a distância de maneira eficiente para se manter uma atividade produtiva que se inicia desde a programação e provimento da matéria prima até a distribuição física do produto acabado.

Assim, a logística pode ser entendida como a ligação entre produtores e consumidores, ou vice-versa, que se utilizam de recursos e atividades para planejar, implementar, controlar e assegurar, de modo eficiente, o fluxo e armazenagem de produtos e serviços desde o ponto de origem até o ponto de consumo, sendo uma função essencial para qualquer negócio (RUTNER; LANGLEY, 2000; MOURA, 2006; BOSONA; GEBRESENBET, 2013; CROUCHER; BAKER, 2014; NOVAES, 2016). Para que exista esse fluxo de produtos e serviços do ponto de origem até o ponto de consumo, uma logística adequada faz-se necessária, não somente com o pensamento no mercado interno, mas no mercado externo igualmente. Em um país de proporção continental, como o Brasil, a logística tem forte influência no fluxo de bens e serviços.

Arbache (2015) indica que o escopo da logística é bastante amplo e chega a englobar processos de gestão, planejamento, execução e controle, abrangendo diferentes campos da economia. Dada a abrangência da logística o presente trabalho focou no serviço de transporte, em especial, o de cargas de origem agropecuária, voltadas para o escoamento no mercado interno e externo.

No Brasil, onde o agronegócio vem ganhando destaque na economia nacional nos últimos anos, a logística representa o principal elo de comunicação e escoamento da produção oriunda da agricultura e pecuária, tornando-se importante para o fluxo de bens e serviços do campo. Indo além, a logística representa um ponto importante para o comércio de produtos agropecuários, haja visto que o custo logístico e perdas ao longo do sistema logístico têm seu peso no valor da produção agropecuária conforme estudos de Martins et al. (2005), Martins (2011), Kussano e Batalha (2009; 2012) e Costabile et al. (2016).

A necessidade de escoamento desta produção agrícola e de outros produtos é, segundo Barat (2009), de responsabilidade da logística e seu serviço de transporte e armazenagem que tem como função escoar as mercadorias destinadas à exportação, ao abastecimento interno e à segurança alimentar. Entretanto, gargalos são encontrados que dificultam esse escoamento da produção agrícola de grãos e outros produtos de origem agropecuária em geral.

De acordo com o relatório de competitividade da World Economic Forum (2015), o Brasil ocupa a 74ํㅜ posição no Ranking Global de Competitividade, de um total de 140 países, no quesito infraestrutura que engloba o caráter logístico. A inexistência de uma infraestrutura adequada é um dos três principais entraves para se realizar negócios no Brasil, empatado com a corrupção. Assim, o país acaba perdendo sua vantagem comparativa, adquirida na produção e produtividade 
agropecuária, na competitividade internacional pela falta de qualidade em seu sistema logístico.

No país, existem inúmeros gargalos de infraestrutura logística. Capdeville (2010) enumera algumas como as ocasionadas pelo ambiente organizacional, pelas condições de estrutura viária, pelas condições das instalações, pela falta de licenças ambientais, pelas ineficiências do setor energético, pelos altos custos - de operação, de transação e de capital - e pela tecnologia empregada.

A existência de gargalos na infraestrutura do sistema logístico do Brasil acarreta perdas de eficiência e aumento de custos para toda a cadeia produtiva nacional, além de apresentar uma barreira para a competitividade do produto brasileiro no comércio internacional (BARAT, 2009; PONTES et al., 2009; CAPDEVILLE, 2010; SOUZA, 2012).

Nesse contexto, o serviço de transporte de cargas torna-se importante por ser o principal meio de escoamento da produção agropecuária, contribuindo com a economia do país, mesmo com limitações em sua infraestrutura. Assim, o presente trabalho pretende analisar as interações entre os gargalos encontrados no serviço de transporte de cargas e os investimentos feitos para minimizar a perda de eficiência gerada. Portanto, o presente trabalho tem como objetivos: (i) traçar um panorama do serviço de transporte de cargas agropecuária no Brasil e (ii) verificar se os investimentos realizados são condizentes com a necessidade logística atual.

Assim, para se atingir os objetivos propostos o trabalho será construído com base numa pesquisa descritiva, focada na análise de dados secundários, e está organizado em cinco partes, sendo esta primeira de introdução. A segunda parte é dedicada ao serviço de transporte de cargas agropecuárias no Brasil; a terceira parte focará nos fatores limitantes; a quarta parte será referente aos investimentos em infraestrutura; e a quinta parte trará as considerações finais.

\section{PANORAMA DO SERVIÇO DE TRANSPORTE E DE CARGAS AGROPECUÁRIAS}

Conforme já contextualizada, a logística é tida por Ballou (2001), Moura (2006) e Novaes (2016) como uma forma eficiente do fluxo de produtos e serviços, do ponto de origem ao ponto de destino, entre produtores e consumidores que englobam recursos e atividades de transporte, armazenamento, informação e comunicação.

De forma a consolidar o entendimento da logística feita anteriormente, Daskin (1985) definiu a logística como sendo o planejamento e operações dos sistemas físicos, informacionais e gerenciais que são necessários para que insumos e produtos ultrapassem as condicionantes espaciais e temporais de forma econômica, isso inclui o serviço de transporte. A Figura 1 ilustra o entendimento de Daskin (1985) sobre o papel da logística. 
Figura 1. Necessidades logísticas (tradução livre).

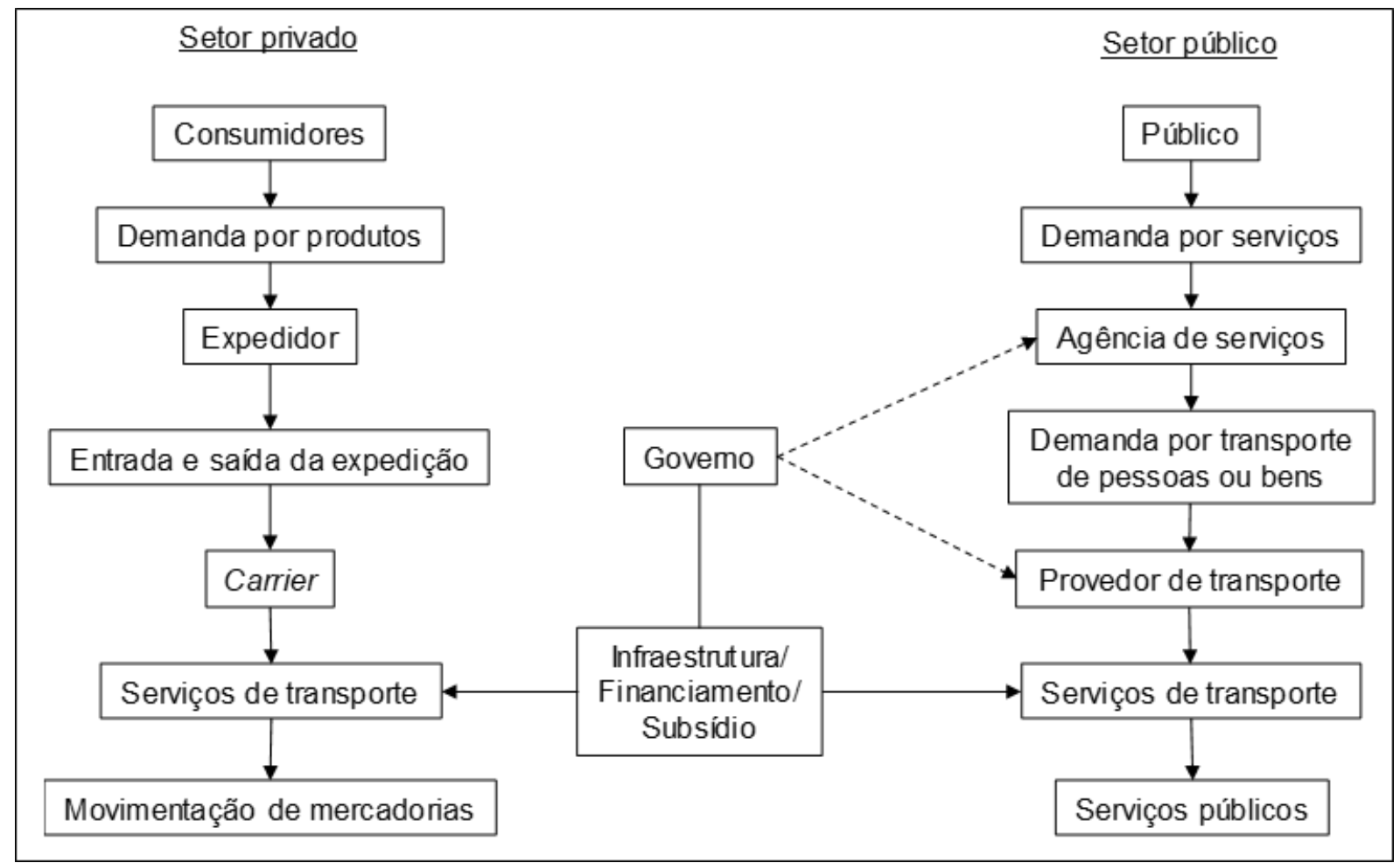

Fonte: adaptado de Daskin, 1985, p.384.

As necessidades da logística encontrada por Daskin (1985) recaem sobre os atores - produtores, expedidores, carries(empresa ou pessoa que transporta mercadorias via terrestre, marítima ou aérea), governos e consumidores - que dependem dos serviços de transporte para ligá-los entre si que tem papel fundamental numa cadeia produtiva. O serviço de transporte ou também chamado de operações de transporte é parte integrante da logística e, por vezes, esses termos são utilizados como sinônimos. Com importância para o planejamento estratégico e abordagens táticas, o serviço de transporte se posiciona como um dos principais pontos da logística atual, responsável por grande parcela no custo logístico e pode gerar uma vantagem competitiva ao produto ou serviço oferecido (BALLOU, 2001; RIBEIRO; FERREIRA, 2002; RODRIGUES, 2008; COUNCIL OF SUPPLY CHAIN MANAGEMENT PROFESSIONALS, 2013).

Alguns autores como Chow et al. (1994), Davidsson et al. (2005), Cruijssen et al. (2007), Rodrigues (2008) e Christopher (2016) definem o serviço de transporte ou somente transporte como a atividade de movimentar algo entre a posição $A$ e $B$, ou seja, movimento de uma carga de um ponto a outro, podendo englobar atividades auxiliares como o planejamento de rota, gerenciamento de frete, agendamento e outras funcionalidades de apoio. Já Grabara et al. (2014) faz um estudo compilando a essência do transporte logístico e aponta que o serviço de transporte é a primeira função da logística que consiste na coleta, entrega e armazenamento do produto. Enquanto Barat (2007) indica o transporte como um dos mais importantes elos das cadeias logísticas e, por consequência, de cadeias produtivas complexas de escala mundial como as industriais, agrícolas, agroindustriais e de exploração de recursos naturais. 
Segundo estudo realizado pelo World Bank (2007), entre 1991 e 2006, o setor de transporte (de cargas) no Brasil cresceu $0,7 \%$ a mais do que o PIB nacional por ano, tendo importância para a economia do país e contribuindo como um elemento chave para o desenvolvimento regional. No período de 10 anos recentes, de 2009 a 2018, o PIB de serviços que inclui o transporte, a armazenagem e o correio, teve uma participação média no PIB total de 4,37\% sendo uma relação estável ao longo dos anos conforme a Figura 2.

Figura 2. Participação do PIB de serviços (correio, transporte e armazenagem) no PIB do Brasil.

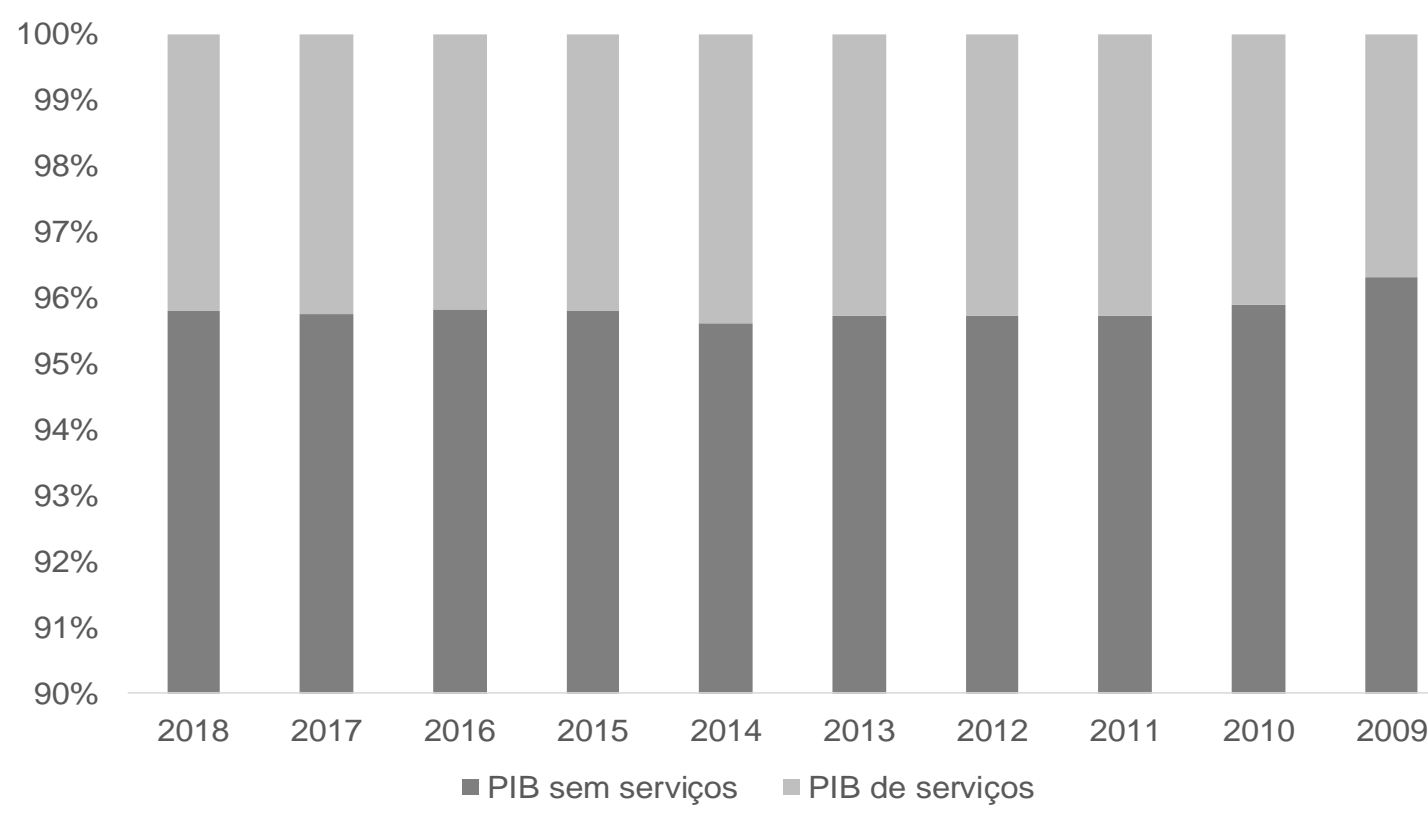

Fonte: elaboração própria.

Nota: dados do Sistema de Contas Nacionais (IBGE, 2018).

Com a base de crescimento do consumo no mundo inteiro, SteadieSeifi et al. (2014) observa que o transporte de cargas tem testemunhado diversas tendências, principalmente após a crise econômica mundial de 2008, onde as empresas buscaram diminuir custos e aumentar o desempenho através da cooperação e integração multimodal, utilizando recursos de forma mais eficiente. $O$ autor ainda conclui que 0 transporte multimodal oferece uma plataforma avançada para um transporte de cargas mais eficiente, confiável, flexível e sustentável.

Para Stock e Lambert (2001) existem cinco tipos de modais diferentes para se realizar o transporte de produtos conhecidos por road, rail, air, water, and pipeline, ou na tradução para português estradas (rodoviário), trilho (ferroviário), ar (aéreo); água (aquaviário) e dutos. A combinação destes modais é tida por McClenehen (1997) como um artificio para as empresas buscarem a redução no custo de transporte e adicionando valor a sua função básica, resultando em uma rede intermodal de transporte globalizado.

O Quadro 2 demonstra de forma resumida cada um dos modais e suas características. 
Quadro 1. Resumo das principais características dos modais de transporte.

\begin{tabular}{|c|c|c|c|c|}
\hline Modal & $\begin{array}{l}\text { Investimento } \\
\text { (implantação) }\end{array}$ & $\begin{array}{l}\text { Dificuldade } \\
\text { da operação }\end{array}$ & $\begin{array}{l}\text { Velocidade } \\
\text { de } \\
\text { transporte }\end{array}$ & Distância ideal \\
\hline Rodoviário & Médio a alto & Baixo & Rápida & Curtas e médias \\
\hline Ferroviário & Alto & Baixo & Baixa & Longas \\
\hline Aéreo & Alto & Alto & Rápida & $\begin{array}{l}\text { Longas e } \\
\text { intercontinentais }\end{array}$ \\
\hline Aquaviário & Médio & Alto & Baixo & $\begin{array}{l}\text { Longas e } \\
\text { intercontinentais }\end{array}$ \\
\hline Dutos & Médio & Baixo & Médio & Médias \\
\hline
\end{tabular}

Fonte: elaboração própria.

Nota: características compiladas de Rondinelli e Berry (2000), Ballou (2001), Stock e Lambert (2001), Hesse e Rodrigue (2004), Arnold et al. (2004), Wanke e Fleury (2006) e Kussano e Batalha (2012).

Com a globalização e a necessidade da agilidade na entrega dos produtos nos mercados, a infraestrutura do serviço de transporte intermodal cresceu e passou a gerar demanda, uma vez que se tornou uma forma confiável de se transportar produtos em segurança, tornando-se um importante elo de conexão entre mercados, sendo importante para o supply chain management, ou gestão de suprimentos (MULLER, 1998; RONDINELLI; BERRY, 2000).

No Brasil, existe a predominância e relativa dependência do transporte de cargas através das estradas (modal rodoviário) muito pela falta de infraestrutura e disponibilidade dos demais modais de transportes. Porém a existência e a utilização dos modais ferroviário e hidroviário podem contribuir com a diminuição nos custos de transporte e aumentar a eficiência da logística no (CASTILLO, 2004; LIMA, 2006; WANKE; FLEURY, 2006; MOURA; BOTTER, 2011; BOZOKY et al., 2014; KAWANO et al., 2014; KATO, 2016; BRANCO et al., 2016).

A matriz de transporte brasileira está dividida como ilustrado na Figura 3.

Figura 3. Matriz de transporte brasileira para o ano de 2014.

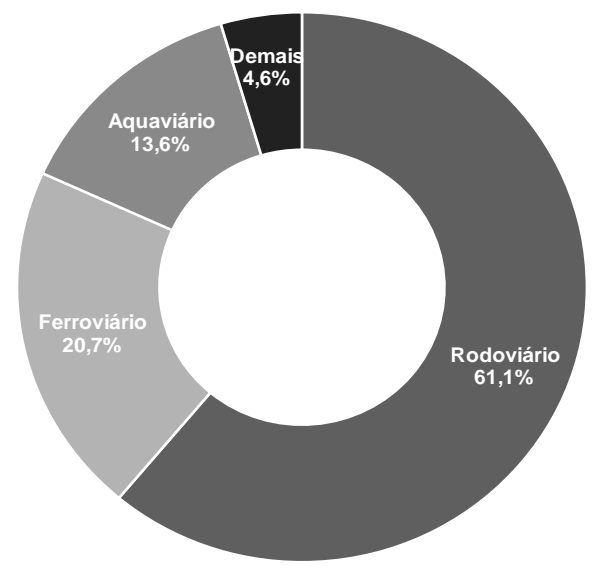

Fonte: elaboração própria. 
Nota: dados da Confederação Nacional do Transporte (CNT, 2014).

Como forma de caracterizar o transporte de cargas ao englobar mais de um tipo de modal disponível, Steadie Seifi et al. (2014) fizeram uma síntese das características dos transportes multimodais.

O Quadro 3 resume essas características e as nomenclaturas dos tipos multimodais disponíveis.

Quadro 2. Características e nomenclatura dos multimodais de transporte.

\begin{tabular}{|llll|}
\hline Transporte & Característica & $\begin{array}{l}\text { Unidade de } \\
\text { transporte } \\
\text { comum }\end{array}$ & Ideal \\
\hline Multimodal & $\begin{array}{l}\text { Transporte de mercadorias } \\
\text { através de uma sequência } \\
\text { que combine, ao menos, } \\
\text { dois tipos de modais de } \\
\text { transporte }\end{array}$ & $\begin{array}{l}\text { Contêiner, } \\
\text { caixas, pallets }\end{array}$ & $\begin{array}{l}\text { Entregas de forma } \\
\text { regular em escala } \\
\text { regional ou nacional } \\
\text { a longa distância }\end{array}$ \\
& $\begin{array}{l}\text { Tipo particular de transporte } \\
\text { multimodal em que a carga }\end{array}$ & $\begin{array}{l}\text { Contêiner, sem } \\
\text { manipulação do }\end{array}$ & $\begin{array}{l}\text { Flexibilidade e } \\
\text { escala }\end{array}$ \\
& $\begin{array}{l}\text { é transportada uma única } \\
\text { unidade }\end{array}$ & produto em si & Planejamento da \\
Co-modal & $\begin{array}{l}\text { Uso eficiente de diferentes } \\
\text { modais por conta própria ou } \\
\text { por combinação }\end{array}$ & Diversificada & $\begin{array}{l}\text { entrega de forma } \\
\text { eficiente }\end{array}$ \\
& $\begin{array}{l}\text { Combinação estruturada, } \\
\text { eficiente e sincronizada de } \\
\text { dois ou mais modos de } \\
\text { transporte }\end{array}$ & - & $\begin{array}{l}\text { Seleção do melhor } \\
\text { modal com base } \\
\text { nas circunstâncias } \\
\text { operacionais }\end{array}$ \\
\hline
\end{tabular}

Fonte: elaboração própria.

Nota: adaptado de SteadieSeifi et al. (2014).

Vertendo-se o serviço de transporte para produtos agropecuários, Caixeta Filho (2010) observa que a organização espacial da produção torna o transporte fator importante na competitividade dos produtos justamente pela composição dos custos de produção, cuja espacialização das zonas produtoras, matérias primas e zona consumidora (até para exportação) aumentam os custos dos produtos agrícolas e agropecuários.

Colaborando com a visão de Caixeta Filho (2010), Castro (2009) já comentava em seu estudo que o custo logístico é um componente relevante na composição do preço final dos produtos aos consumidores e com o aumento da malha rodoviária a partir de 1950, houve a contribuição para a expansão geográfica da produção agropecuária brasileira.

Em termos gerais, o custo de transporte brasileiro é elevado devido principalmente a: (i) concentração da matriz de transporte no modal rodoviário, com predomínio das estradas nas macrorregiões Sul e Sudeste; (ii) regiões de produção agrícolas, principalmente as de fronteira agrícola, com limitação de acesso a qualquer modal de transporte; e (iii) falta de investimento no transporte multimodal que ocasiona efeitos negativos sobre a competitividade das empresas, levando a custos excessivos 
pelo predomínio na utilização de rodovias deixando o transporte relativamente mais caro que em outros lugares do mundo (WORLD BANK, 2007).

A dependência do transporte de cargas agrícolas e agropecuárias pelo modal rodoviário e o aumento dos custos, provenientes deste tipo de transporte, acaba se tornando motivo de preocupação e alvo de estudo ao longo dos anos. Estudos como os de Fujita et al. (2000), Lima (2006), Gurgel (2014) e Oliveira et al. (2015) relatam o custo de transporte como preocupação na logística e distribuição de produtos agrícolas e agropecuários.

Os aumentos nos custos relatados, levaram um outro grupo de pesquisadores a buscar alternativas de diminuição do custo de transporte. Estudos como os de Dalmás et al. (2009), Branco et al. (2010), Almeida e Guilhoto. (2017), Kawano et al. (2015), Pacheco e Pereira Jr (2015) e Bovolenta e Biaggioni (2016) revelam alternativas de transporte para produtos agrícolas pela utilização de multimodais em detrimento ao rodoviário.

Já em estudos como os de Caixeta Filho (1999), Castro (2003) e Correa e Ramos (2010) a política de transportes é o principal enfoque. Nestes estudos, os autores se preocupam em trazer à tona a discussão entre as políticas de transportes elaboradas pelo Governo Federal para a ocupação e produção agropecuária de forma eficiente.

Considerando o modal rodoviário como o principal para transporte de cargas agropecuárias e os custos originários deste modal, a infraestrutura em rodovias demonstrou queda de $1,6 \%$ na quantidade de estradas, passando de um total de 1.748 mil quilômetros de rodovias, para 1.720 mil quilômetros, ao longo dos anos de 2000 e 2010, segundo dados do Ministério dos Transportes (2018). No entanto, o estado geral de conservação das rodovias é considerado, em sua maioria, de ótimo a regular conforme Figura 4.

Figura 4. Situação geral da malha rodoviária brasileira.

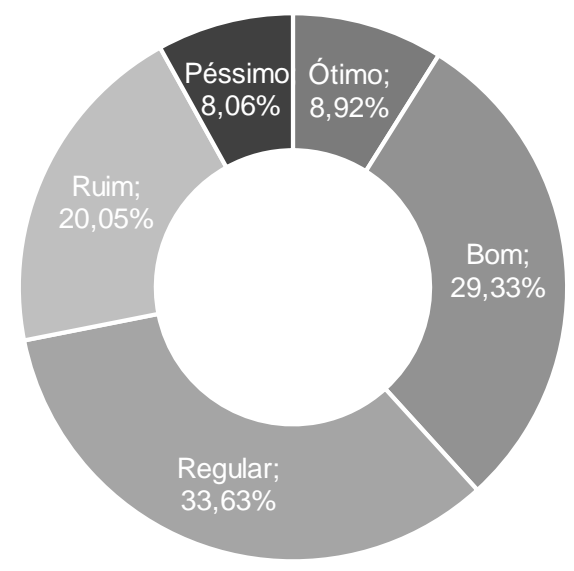

Fonte: elaboração própria.

Nota: dados do Ministério do Transporte (2018).

Assim, o serviço de transporte de cargas agropecuárias brasileira é realizado principalmente pelo modal rodoviário, cuja espacialidade da produção agrícola e o custo oriundo do transporte por este tipo de modal alia-se aos gargalos logísticos impactando na economia e no comércio interno e externo. Com o panorama traçado do serviço de transporte de cargas agrícolas e pecuárias no Brasil é possível explorar 
seus fatores limitantes que acarretam na perda de eficiência e em vantagem comparativa.

\section{Os fatores limitantes}

Os fatores limitantes, ou chamados gargalos são aqueles que dificultam ou até impossibilitam que a logística ocorra de maneira eficiente, semelhante a definição encontrada na Council of Supply Chain Management Professionals (2013) em que o gargalo é "um constrangimento, obstáculo ou controle planejado que limita a produção ou a utilização de sua capacidade" (CSCMP, 2013, p.22, tradução livre ${ }^{5}$ ).

Estudos seminais de Hammer (1969), Garfinkel e Rao (1971) e Bhatia et al. (1976) apontam que o fator limitante da qual deriva todo o resto é o tempo. O tempo de transporte é causador de ineficiências que ocasionam um efeito cascata para a cadeia de suprimentos. Estes autores apontam que a existência do tempo de transporte associado a oferta e demanda de produtos deve ser mínima e ligado a uma viabilidade máxima do transporte de cargas para que se tenha um transporte satisfatório em custo versus tempo.

A importância dos serviços de transportes na translocação de produtos agropecuários torna-se mais crítica ao considerar a sensibilidade ao tempo dos mesmos. Segundo Behar e Venables (2011), Attavanich et al. (2013) e Redding e Turner (2014) a perecibilidade dos produtos de origem vegetal e animal aumentam os custos de transporte, necessitando um maior cuidado e qualidade no serviço de transporte contratado, tornando este tipo de serviço mais restritivo perante que 0 transporte de outros produtos.

A ineficiência do serviço de transporte de cargas - não só agropecuárias gerada pelos gargalos do sistema logístico pode interferir negativamente no custo logístico, na perda de vantagem comparativa e no aumento da ineficiência que prejudica a economia de um país (BALLOU, 2001; RODRIGUES, 2008; BARAT, 2009; KUSSANO e BATALHA, 2009; CAPDEVILLE, 2010; FERNANDES, 2011; KATO, 2016). Assumindo a existência de gargalos nos serviços de transportes buscou-se quais são os fatores limitantes que mais impactam negativamente para o setor logístico, compilando fatores versus autores que os estudaram e seus principais apontamentos sobre a interferência dos gargalos no sistema de transporte de cargas. estudaram.

O Quadro 4 apresenta um resumo dos fatores limitantes e os autores que já as

\footnotetext{
5 "Bottleneck: a constraint, obstacle or planned control that limits throughput or the utilization of capacity" (CSCMP, 2013, p.22).
} 
Quadro 3. Resumo dos autores que estudaram os fatores limitantes do setor logístico brasileiro.

\begin{tabular}{|c|c|c|}
\hline $\begin{array}{l}\text { Fatores } \\
\text { limitantes }\end{array}$ & Autores & Apontamentos \\
\hline Custo / frete & $\begin{array}{l}\text { Fujita et al. (2000); Ledyard } \\
\text { et al. (2002); Hesse e } \\
\text { Rodrigue (2004); World Bank } \\
\text { (2007); Caixeta Filho (2010); } \\
\text { Castro (2012); Mascarenhas } \\
\text { et al. (2014); e Aritua (2016). }\end{array}$ & $\begin{array}{l}\text { O custo ou frete cobrado torna-se } \\
\text { uma barreira na realização de } \\
\text { comércios, sendo fator } \\
\text { determinante para que ocorra ou } \\
\text { não a transação e, em alguns } \\
\text { casos, inviabiliza a produção em } \\
\text { um determinado local. }\end{array}$ \\
\hline $\begin{array}{l}\text { Dependência do } \\
\text { modal rodoviário / } \\
\text { desbalanceamento } \\
\text { da matriz de } \\
\text { transporte }\end{array}$ & $\begin{array}{l}\text { Ledyard et al. (2002); Erhart } \\
\text { e Palmeira (2006); Keil e } \\
\text { Young (2008); Kawano et al. } \\
\text { (2015); Pacheco e Pereira Jr } \\
\text { (2015); Lima (2015); e } \\
\text { Branco et al. (2016). }\end{array}$ & $\begin{array}{l}\text { Com a dependência ou predomínio } \\
\text { de um modal de transporte } \\
\text { logístico eleva-se o custo de } \\
\text { transporte que é fator de } \\
\text { competitividade para determinadas } \\
\text { indústrias. A utilização de } \\
\text { transporte multimodal pode } \\
\text { diminuir os custos e aumentar a } \\
\text { competitividade de setores na } \\
\text { economia. }\end{array}$ \\
\hline $\begin{array}{l}\text { Infraestrutura } \\
\text { logística }\end{array}$ & $\begin{array}{l}\text { Fujita et al. (2000); Castro } \\
\text { (2002); World Bank (2007); } \\
\text { Kussano e Batalha (2009; } \\
\text { 2012); Capdeville (2010); } \\
\text { Mitsutani (2010); Freitas et al. } \\
\text { (2011); Lopes (2015); } \\
\text { Schalch (2016); e Aritua } \\
\text { (2016). }\end{array}$ & $\begin{array}{l}\text { Problemas com infraestrutura são } \\
\text { originários de falta ou falhas na } \\
\text { infraestrutura de transportes. Os } \\
\text { gargalos vão desde problemas } \\
\text { com vias de acesso ou } \\
\text { escoamento (por exemplo buracos, } \\
\text { estradas mal sinalizadas e } \\
\text { dificuldade de acesso), até falhas } \\
\text { no sistema de comunicação } \\
\text { (tecnologia de informação). }\end{array}$ \\
\hline $\begin{array}{l}\text { Eficiência do } \\
\text { serviço de } \\
\text { transportes }\end{array}$ & $\begin{array}{l}\text { Keil e Young (2008); Castro } \\
\text { (2009); Castro (2014); } \\
\text { Mascarenhas et al. (2014); } \\
\text { Tioneli (2014); Lopes (2015); } \\
\text { e Aritua (2016). }\end{array}$ & $\begin{array}{l}\text { A falta de eficiência é gerada pelo } \\
\text { acúmulo de fatores limitantes } \\
\text { (como custo e infraestrutura). } \\
\text { Através disto, gera-se o aumento } \\
\text { do custo logístico e perda de } \\
\text { competitividade. }\end{array}$ \\
\hline $\begin{array}{l}\text { Questões políticas } \\
\text { e sociais }\end{array}$ & $\begin{array}{l}\text { Correa e Ramos (2010), } \\
\text { Capdeville (2010); Drewello e } \\
\text { Günther (2012); Machado } \\
\text { (2013); Cruz (2015); Psaraftis } \\
\text { (2015); Proskurina et al. } \\
\text { (2016); e Perera et al. (2017). }\end{array}$ & $\begin{array}{l}\text { Políticas governamentais e } \\
\text { preocupação socioambiental são } \\
\text { entraves no desenvolvimento do } \\
\text { sistema logístico, pois ocasionam } \\
\text { impactos, em especial, em } \\
\text { construção de infraestrutura. }\end{array}$ \\
\hline
\end{tabular}

Fonte: elaboração própria.

Nota: as bases de dados bibliográficos utilizadas para este levantamento estão relacionadas no Quadro 1.

De acordo com os estudos consultados, é possível relacionar os gargalos do sistema logístico e os serviços de transportes em cinco grandes grupos: custo ou frete; predominância de um modal de transporte sobre os demais; problemas com infraestrutura logística; (in) eficiência dos serviços de transportes; e questões políticas e sociais.

O custo com o transporte é abordado como uma barreira para realização do comércio que pode inviabilizar a produção de determinados produtos em locais específicos devido ao alto custo em se transportar bens e serviços para essas regiões. 
Indo além, outros custos são contabilizados, como os custos de transação (FUJITA et al., 2000; LEDYARD et al., 2002; HESSE; RODRIGUE, 2004; ARITUA, 2016).

Em se tratando do setor agrícola, o custo com o transporte, encontra uma dificuldade em equilibrar o custo compatível com a espacialidade da produção, uma vez que o Brasil tem proporções continentais e há certa dificuldade na movimentação de insumos produtivos de região para região (CAIXETA FILHO, 2010; MASCARENHAS et al., 2014).

Outro impacto para a agropecuária no serviço de transporte está no desbalanceamento da matriz de transporte que prejudica o tempo e o custo, pois o escoamento da produção para atingir os mercados consumidores fica prejudicado e pode afetar diretamente a vantagem comparativa e competitiva obtida em produtos agropecuários, como as commodities agrícolas (KEl; YOUNG, 2008; KAWANO et al., 2015; PACHECO; PEREIRA JR, 2015; LIMA, 2015; BRANCO et al., 2016).

Para a questão de infraestrutura logística os fatores limitantes impactam no sistema logístico como um todo, ocasionando perda de eficiência no transporte, comprometendo o fluxo de bens e serviço entre as regiões, o que prejudica o desenvolvimento da região (FUJITA et al., 2000; CASTRO, 2002; MITSUTANI, 2010; LOPES, 2015; SCHALCH, 2016; ARITUA, 2016).

As questões políticas e socioambiental também são considerados fatores limitantes. Leis, regras, ambiente organizacional, características ambientais (poluição e degradação do meio ambiente) tornam-se barreiras não tarifarias que impactam na melhoria da infraestrutura logística de uma região (CORREA; RAMOS, 2010; CAPDEVILLE, 2010; MACHADO, 2013; CRUZ, 2015; PSARAFTIS, 2015; PROSKURINA et al., 2016). Tais fatores não estão restritos ao Brasil, mas também aparecem no restante do mundo como na Holanda, onde questões políticas para implantação de estradas de Roterdã tornam-se obstáculo para o desenvolvimento da logística (DREWELLO; GÜNTHER, 2012).

Agrupando alguns destes fatores e correlacionando com a produtividade agrícola, Adamopoulos (2011) indica que o transporte pode reduzir os recursos dentro dos setores agrícolas e não agrícolas, devido a disparidades nos custos e nas infraestruturas de transporte, gerando um efeito no comércio internacional porque aumentam-se os custos de entrega das mercadorias. Porém, seu estudo aponta que a melhora na produtividade agrícola pode influenciar positivamente no transporte, através de um processo da transformação estrutural, encorajando melhoria das redes de transporte.

Logo, os fatores limitantes ou gargalo afetam de maneira negativa a competitividade, interferem nas vantagens comparativas adquiridas e mitigam 0 desenvolvimento da logística e dos serviços de transportes. Entretanto, algumas medidas podem ser tomadas, como por exemplo, realização de investimentos para diminuir tais gargalos.

\section{Investimentos em infraestrutura logística}

Após discutir a existência de fatores limitantes, passa-se a questionar o que está sendo feito para minimizar os impactos negativos dos gargalos existentes a fim de proporcionar maiores ganhos de eficiência e com isso melhorar a economia e do desenvolvimento do país.

Sabendo do conflito entre o desenvolvimento e os gargalos logísticos, o Governo Federal criou, em 2007, o Programa de Aceleração do Crescimento (PAC) e dentro 
dele, o Programa de Aceleração do Crescimento de Infraestrutura Logística (PACLOG) com o intuito de promover investimento no setor de logística, fomentando investimentos em portos, aeroportos, rodovias, ferrovias e hidrovias (MINISTÉRIO DO PLANEJAMENTO, 2016a; 2016b).

No ano de 2019, existiam 662 empreendimentos ativos subdivididos em categorias de infraestrutura logística, cada qual com verba do Governo Federal (MINISTERIO DO PLANEJAMENTO, 2019). A Tabela 1 contabiliza os empreendimentos em cada área da logística feito pelo PACLOG.

Tabela 1. Número de empreendimentos por categoria do PACLOG.

\begin{tabular}{lc}
\hline Categorias & Número de empreendimentos \\
\hline Ciência e & 3 \\
tecnologia & 3 \\
Comunicação & 16 \\
Defesa & 117 \\
Aeroportos & 46 \\
Hidrovias & 83 \\
Portos & 20 \\
Ferrovias & 374 \\
\hline Rodovias & $\mathbf{6 6 2}$ \\
\hline Total & \\
\hline
\end{tabular}

Fonte: Ministério do planejamento, 2019.

Com relação aos investimentos realizados, de acordo com o Ministério dos Transportes (2018), foram gastos mais de 220 bilhões entre investimento público e privado de 2010 a 2017.

Com o intuito de diversificar a matriz logística, ponto de gargalo apontado nos estudos de Erhart e Palmeira (2006), Keil e Young (2008), Kawano et al. (2015), Pacheco e Pereira Jr (2015), Lima (2015) e Branco et al. (2016), os investimentos realizados pelo PACLOG e pelo Programa de Investimento em Logística (PIL) fomentam investimentos em todos os modais de transporte, buscando uma redistribuição na matriz de transporte brasileira. Segundo projeção do Governo Federal relatado pelo Plano Nacional de Logística de Transportes (PNLT, 2007) deverá se aproveitar um maior uso dos dos modais ferroviários e aquaviários. A Figura 5 ilustra a matriz de transporte idealizada para 2025. 
Figura 5. Projeção para redistribuição da matriz de transportes para 2025.

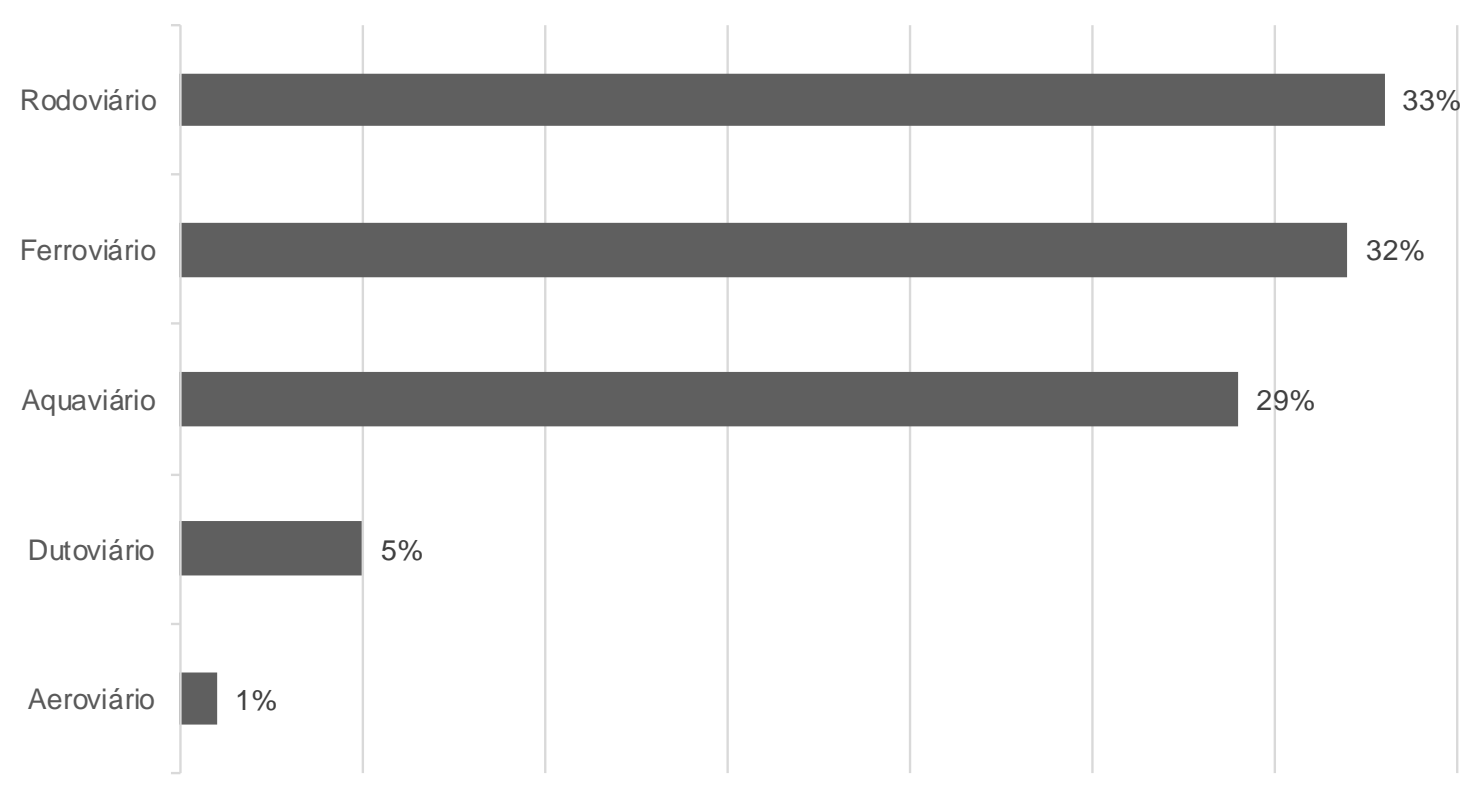

Fonte: elaboração própria.

Nota: dados extraídos da PNLT (MINISTÉRIO DOS TRANSPORTES, 2007).

A comparação entre as Figuras 3 e 5 indica uma melhor distribuição da matriz de transporte, tema que vem se discutindo ao longo das duas últimas décadas. Ojima e Yamakami (2006) afirmam que a redistribuição de maneira eficiente dos transportes de carga no Brasil é uma alternativa importante para potencializar a sua inserção no mercado internacional. A discussão para o escoamento de produtos agrícolas e agropecuários com a melhoria da infraestrutura logística também segue a mesma linha.

Para Medeiros (2014) e Andrade (2015) o PAC e o PNLT retomam o planejamento da infraestrutura logística e de transportes e tem importância significativa para o aumento dos investimentos no sistema logístico, beneficiando o equilíbrio na matriz de transportes e criando um cenário de desenvolvimento regional favorável.

Colaborando com esta ideia, Asai et al. (2017) comentam que as regiões que receberam maiores investimentos em infraestrutura logística são aquelas mais carentes em desenvolvimento e que as políticas públicas estimulam investimentos visam a diminuir os gargalos logísticos e aumentar a competitividade dos produtos brasileiros.

A distribuição espacial dos investimentos em infraestrutura logística pode ser observada na Figura 7. 
Figura 6. Investimentos realizados pelo PACLOG até 2016.
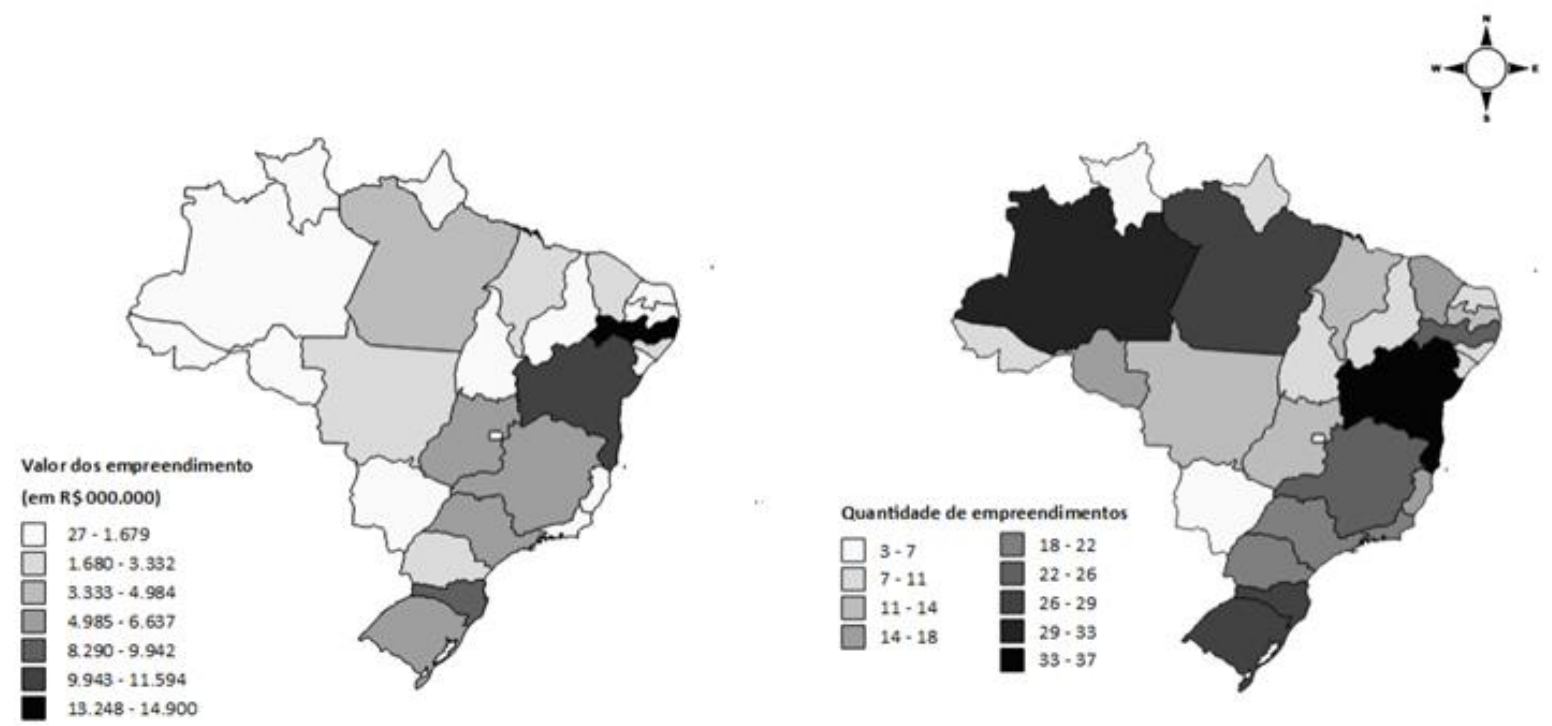

Fonte: Asai et al., 2017, p. 14.

Estudos de caso pontuais como os de Ribeiro e Leite (2014), Maia et al. (2015) e Cunha (2016) demonstram que os investimentos realizados pelo PAC surgem efeitos positivos na melhoria dos serviços de transportes. A modernização, a tecnologia e a melhora na infraestrutura estão entre os pontos de redução no gargalo antes apresentado. Indo além, o Ministério dos Transportes (2018) computa investimentos em logística superiores a 221 bilhões de reais de 2010 a 2017, distribuídos espacialmente conforme a Figura 6. Os estados do sudeste, sul, Bahia e Pernambuco são os que mais receberam investimentos.

Mesmo com os investimentos realizados, um estudo do World Bank (2018) indica que a performance logística brasileira vem decaindo ao longo dos anos. A Figura 7 ilustra a queda.

Figura 7. Índice de performance logística e infraestrutura.

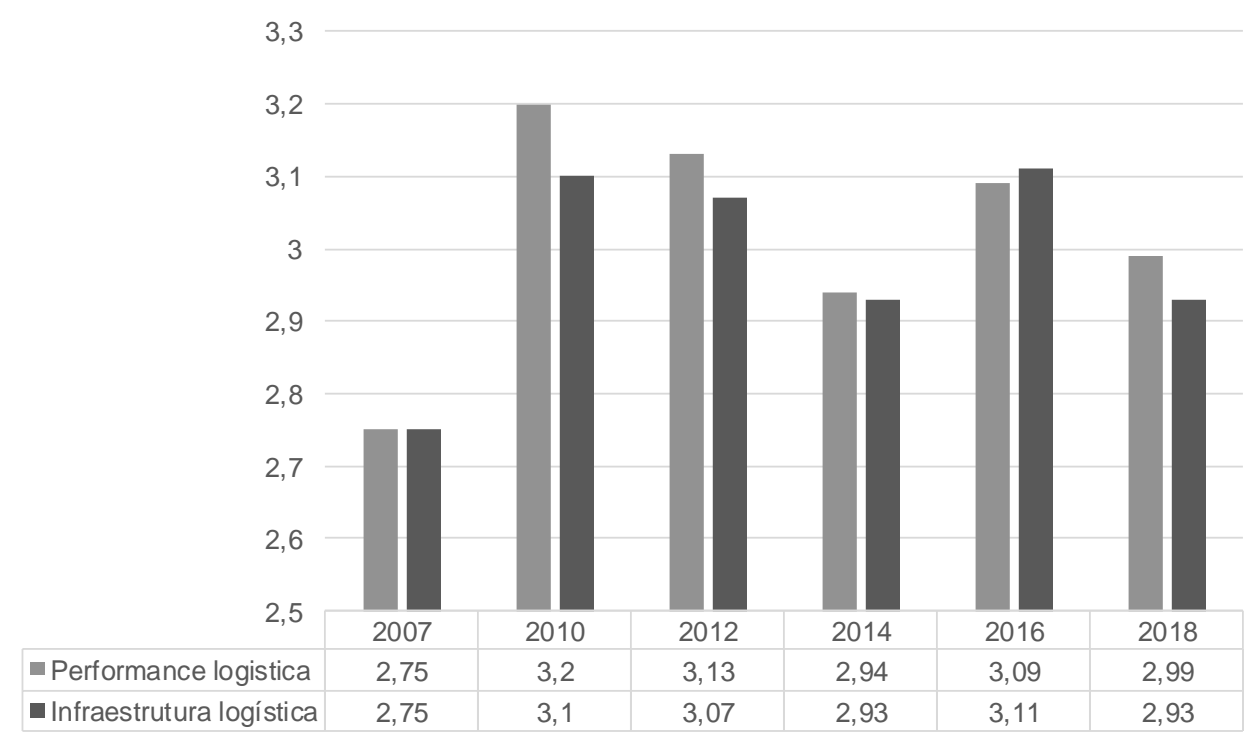

Fonte: elaboração própria.

Nota: dados extraídos do World Bank, 2018. 
Como forma de melhorar a qualidade do sistema logístico brasileiro, a CNT (2018) estipula uma necessidade de 1,7 trilhões de reais em investimento para modernização do sistema logístico brasileiro, distribuídos em $\mathrm{R} \$ 233,3$ bilhões para o norte, $R \$ 257,9$ bilhões no nordeste, $R \$ 260,3$ bilhões para o centro-oeste, $R \$ 696,2$ bilhões no sudeste e $R \$ 281,1$ bilhões no sul.

A julgar a necessidade de 1,7 trilhões de reais para modernização do sistema logístico e diminuição dos gargalos (CNT, 2018), o montante se equivale a $25 \%$ do PIB de 2018 ou mais de 7,67 vezes o total já investido de 2007 a 2018.

Em um exercício de projeção, adotando taxas de crescimento do PIB anual de $1 \%$ e investimento em logística de $0,52 \%$ do PIB (média histórica), o Brasil levará 39 anos a partir de 2019 para atingir a meta da CNT. A projeção está demonstrada na Tabela 2.

Portanto, é necessário que políticas públicas, como o PACLOG, sejam feitas e aceleradas a fim de diminuir os gargalos mencionados e permitir o aproveitamento dos ganhos de eficiência sem perder vantagens comparativas da produção agropecuária ao longo do tempo. Além da infraestrutura propriamente dita, Becker et al. (2012) comentam que o mercado financeiro capaz de suportar os custos de importação e exportação se beneficiaria de uma balança comercial favorável e não estaria exposto as oscilações das taxas de câmbio.

Assim, os investimentos em infraestrutura são importantes para minimizar o custo do transporte, mas há a necessidade no desenvolvimento dos demais setores econômicos para se tirar melhor proveito dos ganhos de eficiência logísticos. Em um contexto geral, os investimentos realizados na melhoria da infraestrutura logística e de transportes são benéficos para o processo de escoamento da produção (incluindo a agrícola), aumento da competitividade dos produtos brasileiros no mercado internacional e o crescimento do Produto Interno Bruto (PIB), integração econômica e desenvolvimento regional e territorial (SILVEIRA, 2013; GARCIA et al., 2015). 
Tabela 2. Projeção de investimentos em logística.

\begin{tabular}{cccc}
\hline Ano & $\begin{array}{c}\text { Investimento } \\
\text { em logística }\end{array}$ & PIB & $\begin{array}{c}\text { Investimentos } \\
\text { acumulados }\end{array}$ \\
\hline 2018 & 35,7 & $6.827 .585,9$ & \\
\hline 2019 & 36,0 & $6.895 .861,8$ & 36,0 \\
\hline 2020 & 36,4 & $6.964 .820,4$ & 72,4 \\
\hline 2021 & 36,7 & $7.034 .468,6$ & 109,1 \\
\hline 2022 & 37,1 & $7.104 .813,3$ & 146,2 \\
\hline 2023 & 37,5 & $7.175 .861,4$ & 183,7 \\
\hline 2024 & 37,8 & $7.247 .620,0$ & 221,5 \\
\hline 2025 & 38,2 & $7.320 .096,2$ & 259,7 \\
\hline 2026 & 38,6 & $7.393 .297,2$ & 298,3 \\
\hline 2027 & 39,0 & $7.467 .230,2$ & 337,3 \\
\hline 2028 & 39,4 & $7.541 .902,5$ & 376,7 \\
\hline 2029 & 39,8 & $7.617 .321,5$ & 416,5 \\
\hline 2030 & 40,2 & $7.693 .494,7$ & 456,7 \\
\hline 2031 & 40,6 & $7.770 .429,6$ & 497,2 \\
\hline 2032 & 41,0 & $7.848 .133,9$ & 538,2 \\
\hline 2033 & 41,4 & $7.926 .615,3$ & 579,6 \\
\hline 2034 & 41,8 & $8.005 .881,4$ & 621,4 \\
\hline 2035 & 42,2 & $8.085 .940,2$ & 663,6 \\
\hline 2036 & 42,6 & $8.166 .799,6$ & 706,3 \\
\hline 2037 & 43,1 & $8.248 .467,6$ & 749,3 \\
\hline 2038 & 43,5 & $8.330 .952,3$ & 792,8 \\
\hline 2039 & 43,9 & $8.414 .261,8$ & 836,8 \\
\hline 2040 & 44,4 & $8.498 .404,5$ & 881,2 \\
\hline 2041 & 44,8 & $8.583 .388,5$ & 926,0 \\
\hline 2042 & 45,3 & $8.669 .222,4$ & 971,2 \\
\hline 2043 & 45,7 & $8.755 .914,6$ & $1.017,0$ \\
\hline 2044 & 46,2 & $8.843 .473,8$ & $1.063,1$ \\
\hline 2045 & 46,6 & $8.931 .908,5$ & $1.109,8$ \\
\hline 2046 & 47,1 & $9.021 .227,6$ & $1.156,9$ \\
\hline 2047 & 47,6 & $9.111 .439,9$ & $1.204,5$ \\
\hline 2048 & 48,1 & $9.202 .554,3$ & $1.252,5$ \\
\hline 2049 & 48,5 & $9.294 .579,8$ & $1.301,0$ \\
\hline 2050 & 49,0 & $9.387 .525,6$ & $1.350,1$ \\
\hline 2051 & 49,5 & $9.481 .400,9$ & $1.399,6$ \\
\hline 2052 & 50,0 & $9.576 .214,9$ & $1.449,6$ \\
\hline 2053 & 50,5 & $9.671 .977,0$ & $1.500,1$ \\
\hline 2054 & 51,0 & $9.768 .696,8$ & $1.551,1$ \\
\hline 2055 & 51,5 & $9.866 .383,8$ & $1.602,6$ \\
\hline 2056 & 52,0 & $9.965 .047,6$ & $1.654,6$ \\
\hline & 52,6 & $10.064 .698,1$ & $1.707,2$ \\
\hline & 3057 & & \\
\hline
\end{tabular}

Fonte: elaboração própria. 


\section{CONSIDERAÇÕES FINAIS}

O presente trabalho analisou os fatores limitantes encontrados no serviço de transporte de cargas, em especial de produtos agropecuários, e os investimentos feitos para minimizar a perda de eficiência gerada, através de um estudo construído com base numa pesquisa descritiva, focada na análise de dados secundários. Para isto, contou-se com dois objetivos que foi traçar um panorama do serviço de transporte de cargas agropecuária no Brasil e verificar se os investimentos realizados são condizentes com a necessidade logística atual.

Trata-se de um tema relevante para pesquisa, uma vez que o Brasil é um dos principais produtores e exportadores de commodities agrícolas do mundo e 0 escoamento da produção agropecuária, tanto para mercado interno, quanto externo, torna-se importante para o desenvolvimento econômico do país. Neste sentido, o transporte de produtos agropecuários é crítico devido a sua especificidade e sensibilidade ao tempo, devido a perecibilidade dos mesmos. Tao logo, seu custo de transporte é alto pela exigência de maiores cuidados e qualidade na translocação do produto, sendo comprovado pelos estudos de Venables (2011), Attavanich et al. (2013) e Redding e Turner (2014). Advém ainda, o aumento do custo pela predominância do transporte via modal rodoviário, cujo estudo de Ledyard et al. (2002) indica ter o custo mais elevado pela utilização de caminhões e pela falta de infraestrutura adequada.

O desbalanceamento da matriz de transporte, assim como o custo, são fatores limitantes para do sistema logístico nacional. Adicionalmente, a qualidade da infraestrutura, a eficiência do serviço de transportes e as questões políticas e socioambientais são outros entrantes para o desenvolvimento da logística. Tais fatores limitantes ocasionam a perda de vantagem comparativa e competitiva que os produtos agropecuários brasileiros possuem frente aos concorrentes mundiais, adquirido por meio da produção agrícola e pecuária. Logo, para que ocorra esta manutenção ou, até mesmo, uma aplicação das vantagens, faz-se necessário investimentos capazes de minimizar os fatores limitantes.

Entretanto, os investimentos realizados até o momento, não foram suficientes para que se tenha melhora na qualidade e modernização do sistema de transporte, principalmente em infraestrutura. Considerando o montante gasto em logística nos últimos 10 anos e a necessidade apontada pela CNT (2018) os investimentos feitos não são compatíveis com a necessidade logística atual ao ponto de projetar-se mais de 30 anos para atingir o valor atual necessário para modernização e minimização dos gargalos no sistema. Assim, a ineficiência do serviço de transporte de cargas prejudica o desenvolvimento regional e força a perde de competitividade da agropecuária, que perde sua vantagem competitiva e comparativa.

Conclui-se, desta maneira, que o serviço de transporte de cargas agropecuárias tem suas limitações e os investimentos necessário para manutenção da competitividade dos produtos agropecuários no cenário mundial estão aquém das necessidades atuais, sendo necessário um maior investimento e políticas públicas que fomentem o setor de transportes. 


\section{REFERÊNCIAS}

ADAMOPOULOS, T. Transportation Costs, Agricultural Productivity, And CrossCountry Income Differences. International Economic Review, v. 52, n. 2, p. 489521, 2011.

ALMEIDA, E. S; GUILHOTO, J. J. M. O custo de transporte como barreira ao comércio na integração econômica: o caso do Nordeste. Revista Econômica do Nordeste, v. 38, n. 2, p. 224-243, 2017.

ANDRADE, R. Plano de logística e transporte: diretrizes para sua elaboração. 2015. 114 f. TCC (Graduação) - Curso de Engenharia Civil, Escola de Engenharia, Universidade Federal do Rio Grande do Sul, Porto Alegre, 2015.

ANTÓN, F. R. Logística del transporte. Universitat Politecnica de Catalunya. Iniciativa Digital Politecnica, 2005.

ARBACHE, F. S. Gestão de logística, distribuição e trade marketing. Editora FGV, 2015.

ARITUA, B. Unlocking the Potential of Freight Logistics in India. World Bank, Washington, DC. World Bank, 2016.

ARNOLD, P; PEETERS, D; THOMAS, I. Modelling a rail/road intermodal transportation system. Transportation Research Part E: Logistics and Transportation Review, v. 40, n. 3, p. 255-270, 2004.

ASAI, G; BIDARRA, Z. S; PINELA, S. R. S. Análise dos investimentos em logística do programa de aceleração do crescimento (PAC): políticas públicas na direção certa?. In: Seminário Internacional sobre Desenvolvimento Regional. Anais... Santa Cruz do Sul: UNISC, 2017.

ATTAVANICH, W; MCCARL, B. A; AHMEDOV, Z; FULLER, S. W; VEDENOV, D. V. Effects of climate change on US grain transport. Nature Climate Change, v. 3, n. 7, p. 638, 2013.

BALLOU, R. H. Gerenciando a Cadeia de Suprimentos: planejamento, organização e logística empresarial. Porto Alegre: Bookman, 2001.

BALLOU, R. H.. Logística empresarial: transportes, administração de materiais e distribuição física. 5 ed. São Paulo: Atlas, 2010.

BARAT, J. Globalização, logística e transporte. In: BARAT, J. Logística e

transporte no processo de globalização: oportunidades para o Brasil. São Paulo: Unesp, 2007.

BALLOU, R. H.. Planejamento das infraestruturas de logística e transporte.

Radar: tecnologia, produção e comércio exterior, Brasília, p.10-13, abr. 2009.

BECKER, B; CHEN, J; GREENBERG, D. Financial development, fixed costs, and international trade. The Review of Corporate Finance Studies, v. 2, p. 1-28, 2012. BHATIA, H. L; SWARUP, K; PURI, M. C. Time-cost trade-off in a transportation problem. Opsearch, v. 13, n. 3-4, p. 129-142, 1976.

BEHAR, A; VENABLES, A. J. Transport costs and international trade. In: PALMA, A; LINDSEY, R; QUINET, E; VICKERMAN, R. A Handbook of Transport Economics. Northampton: Edward Elgar Publishing, 2011. p. 97-115.

BOSONA, T; GEBRESENBET, G. Food traceability as an integral part of logistics management in food and agricultural supply chain. Food control, v. 33, p. 32-48, 2013.

BOVOLENTA, F. C; BIAGGIONI, M. A. M. Energy demands in ethanol logistics from Midwest Brazil to export. Engenharia Agrícola, v. 36, n. 3, p. 408-419, 2016. BOZOKY, M. JR; OLIVEIRA, A. A P; DELIBERADOR, L. R; FORMIGONI, A; JACUBAVICIUS, C. Análise do modal ferroviário no transporte de soja do centro 
oeste aos portos. INOVAE-Journal of Engineering and Technology Innovation (ISSN: 2357-7797), v. 2, n. 1, p. 50-61, 2014.

BOWERSOX, D. J; CLOSS, D. J; COOPER, M. B. Supply chain logistics management. New York, NY: McGraw-Hill, 2002.

BRANCO, J. E. H; CAIXETA FILHO, J. V; XAVIER, C. E. O; LOPES, R. L;

GAMEIRO, A. H. Desenvolvimento de modelo matemático de otimização logística para o transporte multimodal de safras agrícolas pelo corredor centro-oeste. Informe Gepec, v. 14, n. 1, p. 84-100, 2010.

BRANCO, J. E. H; CAIXETA FILHO, J. V; GAMEIRO, A. H; XAVIER, C. E. O; PINHEIRO, M. A; SOUZA, W. A. Otimização logística para o transporte multimodal de safras agrícolas no Brasil com foco no corredor Nordeste. Revista econômica do nordeste, v. 43, n. 1, p. 67-92, 2016.

CAIXETA FILHO, J. V. Sobre a competitividade do transporte no agribusiness brasileiro. In: Congresso Brasileiro de Economia e Sociologia Rural (Sober). Foz do Iguaçu, 1999. Anais... Foz do Iguaçu: Sober, 1999.

CAIXETA FILHO, J. V. Logística para a agricultura brasileira. Revista Brasileira de Comércio Exterior, v. 103, p. 18-30, 2010.

CAPDEVILLE, A. Categorização dos gargalos de uma cadeia logística de transporte da safra agrícola. 2010. XV, 87 f. il. Dissertação (Mestrado em Transporte Urbano) - Universidade de Brasília, Brasília, 2010.

CASTILLO, R. Transporte y logística de graneles sólidos agrícolas: componentes estructurales del nuevo sistema de movimientos del territorio brasileño. Investigaciones geográficas, n. 55, p. 79-96, 2004.

CASTRO, N. Custos de Transporte e Produção Agrícola no Brasil: 19701996. Agricultura em São Paulo, v. 49, p. 87-109, 2002.

CASTRO, N. Expansão rodoviária e desenvolvimento agrícola dos cerrados. 2003.

CASTRO, N. Infraestrutura de transporte e expansão da agropecuária

brasileira. Planejamento e políticas públicas, n. 25, 2009.

CASTRO, C. N. A agropecuária na região Centro-Oeste: limitações ao

desenvolvimento e desafios futuros. Texto para Discussão, Instituto de Pesquisa Econômica Aplicada (IPEA), 2014.

CHOW, G; HEAVER, T. D; HENRIKSSON, L. E. Logistics performance: definition and measurement. International journal of physical distribution \& logistics management, v. 24, n. 1, p. 17-28, 1994.

COMPANHIA NACIONAL DE ABASTECIMENTO - CONAB. Informações agropecuárias: série histórica. 2019.

CONFEDERAÇÃO NACIONAL DO TRANSPORTE - CNT. Plano CNT de Transporte e Logística 2018. 2018

CORREA, V. H. C; RAMOS, P. Evolução das políticas públicas para a agropecuária brasileira: uma análise da expansão da soja na região centro-oeste e os entraves de sua infraestrutura de transportes. Informações Econômicas, v. 40, n. 10, p. 5-16, 2010.

COSTABILE, L. T; VENDRAMETTO, O; OLIVEIRA NETO, G. C. Comparativo de perdas de grãos no transporte rodoviário-Estudo de Caso. Revista ESPACIOS. v. 37, n. 15, 2016.

CONFEDERAÇÃO NACIONAL DO TRANSPORTE. Plano CNT de transporte e logística 2014. Brasília: CNT, 2014.

CONFEDERAÇÃO NACIONAL DO TRANSPORTE _. Plano CNT de transporte e logística 2018. Brasília: CNT, 2018. 
COUNCIL OF SUPPLY CHAIN MANAGEMENT PROFESSIONALS. Supply Chain Management Terms and Glossary. Illinois: CSCMP, 2013.

CROUCHER, P; BAKER, P. The handbook of logistics and distribution management: Understanding the supply chain. Kogan Page Publishers, 2014.

CRUIJSSEN, F; DULLAERT, W; FLEUREN, H. Horizontal cooperation in transport and logistics: a literature review. Transportation journal, p. 22-39, 2007.

CRUZ, W. L M. O complexo portuário do Itajaí: o papel das políticas institucionais, dos investimentos em infraestruturas e das empresas de transportes e logística na dinâmica de movimentação de cargas. In: Encontro Nacional da ANPEGE, 11, 2015, Presidente Prudente. Anais... Presidente Prudente: UFGD Editora, p. 2015.

CUNHA, C. N. Reforma da Logística Portuária no espaço brasileiro. Revista Grifos, v. 25, n. 40, p. 183-207, 2016.

DALMÁS, S. R. S. P; SILVA LOBO, D; ROCHA JR, W. F. A logística de transporte agrícola multimodal da região oeste paranaense. Informe Gepec, v. 13, n. 2, p. 154169, 2009.

DASKIN, M. S. Logistics: an overview of the state of the art and perspectives on future research. Transportation Research Part A: General, v. 19, n. 5-6, p. 383398, 1985.

DAVIDSSON, P; HENESEY L; RAMSTEDT, L; TÖRNQUIST, J; WERNSTEDT F. An analysis of agent-based approaches to transport logistics. Transportation Research part C: emerging technologies, v. 13, n. 4, p. 255-271, 2005.

DEPARTAMENTO DO AGRONEGÓCIO (DEAGRO). Balança Comercial Brasileira do Agronegócio - Consolidado 2019. São Paulo: Federação das Indústrias do Estado de São Paulo, 2019. (Informativo DEAGRO).

DEPARTAMENTO DO AGRONEGÓCIO (DEAGRO).. Safra Brasileira de Grãos 2018/19 - 8. Levantamento da Conab. São Paulo: Federação das Indústrias do Estado de São Paulo, 2019b. (Informativo DEAGRO).

DREWELLO, H; GÜNTHER, F. Bottlenecks in railway infrastructure-do they really exist? The Corridor Rotterdam-Genoa. In: European Transport Conference. Anais... Rotterdam: Association for European Transport (AET) Transportation Research Board. 2012.

ERHART, S; PALMEIRA, E. M. Análise do setor de transportes. Observatório de la Economía Latinoamericana, v. 1, p. 71, 2006.

FEIJÓ, F. T; STEFFENS, C. International trade, labor allocation and the issue of deindustrialization in Brazil: an approach using computable general

equilibrium. Revista de Economia Contemporânea, v. 19, n. 1, p. 135-161, 2015.

FERNANDES, D. M. T. As vantagens comparativas brasileiras no comércio bilateral de soja com a China. 2011. TCC (bacharelado - Ciências Econômicas) -

Universidade Estadual Paulista, Faculdade de Ciências e Letras de Araraquara, 2011.

FREITAS, R. E; MENDONÇA, M. A. A; LOPES, G. O. Expansão de área agrícola nas mesorregiões brasileiras. Revista de Política Agrícola, v. 20, n. 1, p. 100-116, 2011.

FUJITA, M; KRUGMAN, P. R; VENABLES, A J. Economía espacial: las ciudades, las regiones y el comercio internacional. Ariel, 2000.

GARCIA, S; VICENS-SALORT, E; NAAS, I. A. Investimentos em transporte intermodal no brasil poderia beneficar o crescimento do PIB. Revista Brasileira de Engenharia de Biossistemas, v. 9, n. 1, p. 90-98, 2015. GARFINKEL, R. S; RAO, M. R. The bottleneck transportation problem. Naval Research Logistics, v. 18, n. 4, p. 465-472, 1971. 
GRABARA, J; KOLCUN, M; KOT, S. The role of information systems in transport logistics. International Journal of Education and Research, v. 2, n. 2, p. 1-8, 2014. GURGEL, A. C. Impactos de políticas comerciais e agrícolas sobre a agropecuária e agroindústria brasileiras. In: Congresso da Sociedade Brasileira de Economia e Sociologia Rural, 52, 2014, Goiânia. Anais... Goiânia: Sober, 2014.

HAMMER, P. L. Time-minimizing transportation problems. Naval Research Logistics, v. 16, n. 3, p. 345-357, 1969.

HESSE, M RODRIGUE, J. P. The transport geography of logistics and freight distribution. Journal of transport geography, v. 12, n. 3, p. 171-184, 2004. HUMMELS, D; SCHAUR, G. Time as a trade barrier. National Bureau of Economic Research, v. 103, n. 7, p. 2935-59, 2012.

INSTITUTO BRASILEIRO DE GEOGRAFIA E ESTATÍSTICA (IBGE). Sistema de Contas Nacionais. Brasília. 2018.

KAWANO, B. R; MORES, G. V; SILVA, R. F; CUGNASCA, C. E. Estratégias para resolução dos principais desafios da logística de produtos agrícolas exportados pelo Brasil. Revista de Economia e Agronegócio-REA, v. 10, n. 1, 2015.

KEIL, R; YOUNG, D. Transportation: the bottleneck of regional competitiveness in Toronto. Environment and Planning C: Government and Policy, v. 26, n. 4, p. 728-751, 2008.

KUSSANO, M. R; BATALHA, M. O. Custos logísticos do escoamento do açúcar brasileiro para o mercado externo. In: Encontro Nacional de Engenharia de Produção, 29, 2009, Salvador. Anais... . Salvador: Enegep, 2009.

KUSSANO, M. R; BATALHA, M. Custos logísticos agroindustriais: avaliação do escoamento da soja em grão do Mato Grosso para o mercado externo. Gestão e Produção, São Carlos, v. 19, n. 3, 2012.

LEDYARD, J. O; OLSON, M; PORTER, D; SWANSON, J. A; TORMA, D. P. The First Use of a Combined-Value Auction for Transportation Services. Interfaces, [s.I.], v. 32, n. 5, p.4-12, out. 2002. Institute for Operations Research and the Management Sciences (INFORMS).

LIMA, M. P. Custos logísticos na economia brasileira. Revista Tecnologística, v. 11, n. 122 , p. 64-69, 2006.

LIMA, R. C. O uso corporativo do território pelo agronegócio e a questão da logística de transportes em Mato Grosso. 2015. 278 f., il. Tese (Doutorado em Geografia) Universidade de Brasília, Brasília, 2015.

LOPES, B. F. R. Dinâmica da logística do milho brasileiro: uma aplicação de um modelo de equilíbrio espacial. 2015. 76 f. Tese (Doutorado) - Curso de Engenharia Elétrica, Universidade Estadual de Campinas, Campinas, 2015.

MACHADO, R. A. Políticas de infraestrutura econômica logística e arranjos de coordenação na administração pública federal brasileira no governo Lula. Revista Eletrônica de Ciência Política, v. 4, n. 1-2, 2013.

MAIA, W. B; HARTMANN, T. C; BUENO, B. A. F; KAPP JUNIOR, C. Proposição de um plano de gerenciamento logístico frente a problemas da falta de controle de custos em uma Cooperativa Agrícola de Ponta Grossa. Revista de Gestão e Organizações Cooperativas, v. 1, n. 2, p. 27-38, 2015.

MARTINS, R. S. Estudo da formação do frete rodoviário e potencial de conflitos em negociações em cadeias do agronegócio brasileiro. Organizações Rurais \& Agroindustriais, v. 10, n. 1, p.75-89,2011.

MARTINS, R. S; REBECHI, D; PRATI, C. A; CONTE, H. Decisões estratégicas na logística do agronegócio: compensação de custos transporte-armazenagem para a 
soja no estado do Paraná. Rev. adm. contemp., Curitiba, v. 9, n. 1, p. 53-78, mar. 2005.

MASCARENHAS, C. S; LOPES, B. F. R; COLETI, J. C; OLIVEIRA, A. L. R; YAMAKAMI, A. Aplicação de um modelo de localização para a questão logística da soja brasileira: uma indicação de localização para armazéns. Blucher Marine Engineering Proceedings, v. 1, n. 1, p. 686-698, 2014. MCCLENEHEN, J.S. Winning in a world without boundaries: logistics and distribution. Industry. 1997.

MEDEIROS, P. V M. Políticas de infraestrutura de transportes no Brasil: investimentos, multimodalidade e configuração regional no plano nacional de logística e transporte (PNLT). 2014. 176 f. Dissertação (Mestrado em Ciências Sociais Aplicadas) - Universidade Federal de Uberlândia, Uberlândia, 2014. MITSUTANI, C. A logística do etanol de cana-de-açúcar no Brasil: condicionantes e perspectivas. 2010. Dissertação (Mestrado em Energia) Universidade de São Paulo, São Paulo, 2010. MINISTERIO DA AGRICULTURA, PECUÁRIA E ABASTACEIEMNTO - MAPA. Valor bruto da produção agropecuária (VBP). Brasília. 2019. MINISTÉRIO DA ECONOMIA, INDUSTRIA, COMÉRCIO EXTERIOR E SERVIÇOS. Estatísticas do comércio exterior. 2019. MINISTÉRIO DO PLANEJAMENTO. Sobre o PAC. Brasil, 2016a. MINISTÉRIO DO PLANEJAMENTO. Invista em Logística. Brasil, 2016b. MINISTÉRIO DO PLANEJAMENTO. Infraestrutura Logística. Brasil, 2019. MINISTÉRIO DOS TRANSPORTES. Plano Nacional de Logística de Transportes (PNLT): Relatório Executivo 2007. Brasília: Ministério dos Transportes, 2007. MINISTÉRIO DO PLANEJAMENTO. Anuário estatístico de transportes 2010 2017. Brasília: Ministério dos Transportes, 2018.

MOURA, B. Logística: conceitos e tendências. Lisboa: Centro Atlântico, 2006. MOURA, D. A; BOTTER, R. C. O transporte por cabotagem no Brasil-potencialidade para a intermodalidade visando a melhoria do fluxo logístico. Revista Produção Online, v. 11, n. 2, p. 595-617, 2011.

MULLER, G. The business of intermodal freight transportation. Transportation Quarterly,v. 52, pp. 7-11. 1998.

NOVAES, A. G. Logística e gerenciamento da cadeia de distribuição. Elsevier Brasil, 2016.

OJIMA, A. L. R. O; YAMAKAMI, A. Modelo de programação quadrática para análise da movimentação logística e comercialização da soja brasileira. Revista Engenharia Agrícola, Jaboticabal, v. 26, n. 2, p. 552-560, maio/ago. 2006.

OLIVEIRA, A. L. R; CICOLIN, L; SANTOS, M. C. Estimativa do custo rodoviário da soja: uma análise da rota Sorriso-Santos. Revista de Economia e AgronegócioREA, v. 11, n. 2, 2015.

PACHECO, D. A. J; PEREIRA JR, J. L. Implicações e desafios da logística de transporte no agronegócio brasileiro. Gestão Contemporânea, v. 5, n. 2, 2015. PERERA, S; SIRIWARDANA, M; MOUNTER, S. Trade Facilitation-Measurement Difficulties in the Computable General Equilibrium Model: A Review. Theoretical Economics Letters, v. 7, n. 02, p. 154-163, 2017.

PONTES, H. L. J; CARMO, B. B. T; PORTO, A. J. V. Problemas logísticos na exportação brasileira da soja em grão. Sistemas \& Gestão, v. 4, n. 2, p. 155-181, 2009.

PROSKURINA, S; RIMPPIB, H; HEINIMÖC, J; HANSSOND, J; RAGHUF, A. O; VAKKILAINENA, KC E. Logistical, economic, environmental and regulatory 
conditions for future wood pellet transportation by sea to Europe: The case of Northwest Russian seaports. Renewable And Sustainable Energy Reviews, [s.I.], v. 56, p.38-50, abr. 2016. Elsevier.

PSARAFTIS, H. N. Green Transportation Logistics: The Quest for Win-Win Solutions. Springer, 2015.

REDDING, S. J; TURNER, M. A. Transportation costs and the spatial organization of economic activity. In: Handbook of regional and urban economics. Elsevier, 2015. p. 1339-1398.

RIBEIRO, L. C. S; LEITE, A. P. V. Análise estrutural dos investimentos do PAC em infraestrutura logística no estado da Bahia. Análise Econômica, v. 32, n. 62, 2014. RIBEIRO, P. C. C; FERREIRA, K. A. Logística e transportes: uma discussão sobre os modais de transporte e o panorama brasileiro. In: XXII Encontro Nacional de Engenharia de Produção,22, 2002. Anais... Curitiba: ENEGEP, 2002.

RODRIGUES, P. R. A. Introdução aos sistemas de transporte no Brasil e à logística internacional. Edições Aduaneiras, 2008.

RONDINELLI, D; BERRY, M. Multimodal transportation, logistics, and the environment: managing interactions in a global economy. European Management Journal, v. 18, n. 4, p. 398-410, 2000.

RUTNER, S. M; LANGLEY, C. J. Logistics value: definition, process and measurement. The International Journal of Logistics Management, v. 11, n. 2, p. 73-82, 2000.

SCHALCH, E. J. Os gargalos logísticos das principais rotas de escoamento de grãos de soja do estado do Mato Grosso: um estudo de caso do complexo portuário Miritituba-Barcarena no Pará. 2016. Dissertação (Mestrado em Gestão e Inovação na Indústria Animal) - Faculdade de Zootecnia e Engenharia de Alimentos, Universidade de São Paulo, Pirassununga, 2016.

SILVEIRA, M. R. Infraestruturas e logística de transportes no processo de integração econômica e territorial. Mercator, Fortaleza, v. 12, p. 41-53, 2013.

SOUZA, L. L. A Logística da Soja na Fronteira Agrícola Norte e Nordeste. 2012. Tese (Doutorado em Logística Agroindustrial) Universidade de São Paulo, Escola Superior de Agricultura "Luiz de Queiroz", Piracicaba.

STEADIESEIFI, M; DELLAERT, N.P; NUIJTEN, W; VAN WOENSEL, T; RAOUFI, R. Multimodal freight transportation planning: A literature review. European journal of operational research, v. 233, n. 1, p. 1-15, 2014.

STOCK, J. R; LAMBERT, D. M. Strategic logistics management. Boston, MA: McGraw-Hill/Irwin, 2001.

WANKE, P. F; FLEURY, P. F. Transporte de cargas no Brasil: estudo exploratório das principais variáveis relacionadas aos diferentes modais e às suas estruturas de custos. In: DE NEGRI, J. A; KUBOTA, L. C. Estrutura e Dinâmica do Setor de Serviços no Brasil. Brasília: IPEA, p. 409-464, 2006.

WORLD BANK. Brazil Evaluating the Macroeconomic and Distributional Impacts of Lowering Transportation Costs, 2007. Document of the World Bank. Mimeografado. WORLD BANK. The Logistics Performance Index and Its Indicators. 2018. WORLD ECONOMIC FORUM. Global Competitiveness Report 2015-2016. EUA: World Economic Forum, 2015. 